\title{
Penerapan Model UTAUT 2 Untuk Mengetahui Faktor-Faktor yang Memengaruhi Penggunaan SIORTU
}

\author{
Nur Azmi Ainul Bashir ${ }^{1}$ \\ ${ }^{1}$ Jurusan Teknik Informatika Fakultas Teknologi Industri Universitas Islam Indonesia \\ E-mail: nurazmiab.4231@gmail.com
}

\begin{abstract}
The parent's academic information system service (SIORTU) has been implemented on campuses, one of them is the Indonesian Islamic University (UII). The official name of SIORTU UII is UNISYS for Parents. There have not been many parents who use SIORTU. Only 7.361 accounts who active between April 2018 and March 2019. The amount is only 36,68\% of the number of accounts provided for parents of students from 2015-2018 namely 20,068 accounts. This research is research development of research that has been done before. This research is quantitative research. Data that has been analyzed represents the research data developed. The purpose of this research was to determine the effect of the factors SIORTU usage behavioral on the SIORTU behavioral intention, as well as knowing how the relationship between the results of research with the results of research developed. The benefit expectations are to strengthen the research developed, know the factors that influence intention and usage of SIORTU and to add references on information system especially SIAKAD and SIORTU. The author assumes variables which includes performance expectancy, effort expectancy, social influence, facilitating conditions and habit its effect to SIORTU behavioral intention and influence SIORTU behavioral intention to SIORTU usage behavioral. The result of the analysis is that all independent variables had a positive influence on behavioral intention and usage behavior through behavioral intention.
\end{abstract}

Keywords: Academic Information System, Parents, UTAUT

\begin{abstract}
ABSTRAK
Layanan sistem informasi akademik untuk orang tua (SIORTU) telah banyak diterapkan di kampuskampus, salah satunya adalah Universitas Islam Indonesia (UII). Nama resmi SIORTU UII yaitu UNISYS untuk orang tua. Belum banyak orang tua atau wali mahasiswa yang menggunakan SIORTU. Tercatat hanya 7.361 akun SIORTU yang aktif pada rentang April 2018 s.d Maret 2019. Jumlah tersebut hanya 36.68\% dari jumlah akun yang disediakan untuk orang tua mahasiswa angkatan 2015-2018 yaitu 20.068 akun. Penelitian ini merupakan pengembangan penelitian yang telah dilakukan sebelumnya. Penelitian ini merupakan penelitian kuantitatif. Data yang dianalisis diperoleh dari data penelitian yang dikembangkan. Tujuan penelitian ini adalah mengetahui pengaruh faktor-faktor penggunaan SIORTU terhadap minat penggunaan SIORTU, serta mengetahui bagaimana hubungan hasil penelitian dengan hasil penelitian yang dikembangkan. Manfaat yang diharapkan antara lain memperkuat hasil penelitian yang dikembangkan, mengetahui faktor-faktor yang memengaruhi minat dan penggunaan SIORTU serta menambah referensi penelitian mengenai sistem informasi khususnya SIAKAD dan SIORTU. Penulis mengasumsikan variabel-variabel penelitian yang meliputi performance expectancy, effort expectancy, social influence, facilitating conditions dan habit berpengaruh terhadap SIORTU behavioral intention dan SIORTU behavioral intention berpengaruh terhadap SIORTU usage behavioral. Hasil Pengujian dan analisis yang dilakukan menghasilkan semua variabel independen berpengaruh positif terhadap behavioral intention dan usage behavioral melalui minat penggunaannya.
\end{abstract}

Kata kunci: Sistem Informasi Akademik, Orang Tua, UTAUT

\section{PENDAHULUAN}

Sistem Informasi Akademik (SIAKAD) khusus orang tua/wali mahasiswa (selanjutnya disebut SIORTU) merupakan pengembangan dari SIAKAD yang digunakan oleh mahasiswa. Perbedaan keduanya adalah pengguna dan akses ke dalam layanan. SIAKAD digunakan oleh mahasiswa untuk berbagai aktivitas akademik seperti melakukan key-in mata kuliah, mengetahui jadwal perkuliahan dan/atau ujian, mengetahui nilai hasil ujian, mengetahui jumlah tagihan keuangan serta pengelolaan data mahasiswa dan lain-lain [1], [2]. SIORTU digunakan oleh orang tua/wali mahasiswa untuk memantau kegiatan akademik anaknya [2]. Mahasiswa dapat melakukan pengelolaan pada 
akun SIAKAD miliknya, sedangkan menggunakan SIORTU, orang tua hanya bisa melihat aktivitas akademik anaknya.

Saat ini, telah banyak perguruan tinggi yang menerapkan SIORTU. Salah satu kampus yang telah menerapkan layanan SIORTU yaitu Universitas Islam Indonesia (UII). UII telah menggunakan SIORTU sejak tahun 2002-an. Menurut pihak Badan Sistem Informasi (BSI) UII yang mengelola layanan ini, SIORTU digunakan untuk memantau berbagai aktivitas akademik mahasiswa oleh orang tua/wali [3]. Aktivitas akademik yang dimaksud antara lain memantau nilai, absensi, konsentrasi studi, jadwal perkuliahan dan beberapa tagihan keuangan. Adapun tagihan keuangan yang dimaksud antara lain tagihan SPP, Catur Dharma, biaya Kuliah Kerja Nyata $(\mathrm{KKN})$ maupun biaya administrasi perpustakaan.

Banyak di antara orang tua/wali mahasiswa UII yang menggunakan SIORTU [3]. Menurutnya, tercatat 7.361 akun aktif dalam rentang waktu April 2018 sampai dengan Maret 2019 dari 20.068 akun yang disediakan untuk orang tua/wali mahasiswa angkatan 2015-2018. Jumlah tersebut menunjukkan hanya sekitar $36.68 \%$ akun saja yang aktif dalam rentang waktu tersebut.

Penelitian ini merupakan pengembangan dari penelitian yang dilakukan oleh Bashir [3]. Tujuan penelitian ini adalah mengetahui pengaruh faktor-faktor penggunaan SIORTU terhadap minat penggunaan SIORTU, serta mengetahui bagaimana hubungan hasil penelitian dengan hasil penelitian yang dikembangkan. Data yang dianalisis pada penelitian ini dibatasi hanya menggunakan hasil perolehan data dari responden oleh Bashir [3]. Adapun jumlah responden penelitiannya yaitu sebanyak 73 orang tua/wali mahasiswa UII yang pernah menggunakan SIORTU. Kerangka pemikiran yang digunakan yaitu modifikasi kerangka model UTAUT 2.

Penelitian Bashir menganalisis faktorfaktor yang memengaruhi penggunaan SIORTU, diantaranya adalah performance expectancy, effort expectancy, social influence, facilitating conditions, habit dan behavioral intention [3]. Penelitian tersebut dilakukan untuk mengetahui faktor-faktor yang memengaruhi penggunaan SIORTU dan alasan mengapa faktor-faktor yang ada termasuk di dalamnya. Kerangka pemikiran penelitian disusun berdasarkan hasil penelitianpenelitian yang menyatakan suatu variabel berpengaruh positif signifikan terhadap minat dan penggunaan suatu sistem.

Berbeda dengan kebanyakan penelitian mengenai penggunaan suatu sistem, Bashir mengasumsikan bahwa performance expectancy, effort expectancy dan social influence berpengaruh langsung terhadap perilaku penggunaan [3]. Hal tersebut didasari oleh penelitian Febrianti yang menyatakan ekspektasi kinerja, ekspektasi usaha, faktor sosial dan kondisi yang memfasilitasi pemakai memengaruhi penggunaan sistem berbasis komputer secara parsial [4] dan penelitian Agustina yang menyatakan variabel-variabel independen penelitiannya yang meliputi ekspektasi kinerja, ekspektasi usaha, faktor sosial dan kepuasan pemakai, memberikan pengaruh terhadap penggunaan sistem informasi [5]. Perbedaan lain yaitu behavioral intention dijadikan sebagai variabel bebas. Berdasarkan penelitian-penelitian terdahulu, behavioral intention belum tentu dipengaruhi oleh variabel bebas [3]. Adapun variabel-variabel bebas yang dipilih oleh Bashir diperoleh dari identifikasi variabel-variabel penelitian sebelumnya.

Perbedaan lain antara penelitian Bashir dan penelitian sebelumnya yaitu variabel behavioral intention. Variabel tersebut merupakan variabel bebas pada penelitian Bashir [3]. Asumsi ini berbeda dengan Venkatesh et al yang menjadikan behavioral intention sebagai variabel penghubung dengan tiga variabel yang memengaruhinya yaitu performance expectancy, effort expectancy dan social influence [6]. Beberapa penelitian belum bisa membuktikan bahwa variabel yang diasumsikan memengaruhi behavioral intention [7]-[9].

Analisis yang dilakukan oleh Bashir menggunakan pengujian nilai original sample estimate dan nilai $T$ statistics [3]. Nilai original 
sample estimate digunakan untuk mengetahui arah pengaruh antara variabel bebas terhadap variabel terikat. Nilai $T$ statistics menunjukkan seberapa signifikan variabel bebas terhadap variabel terikat. Adapun data yang dianalisis berjumlah 73 .

Berdasarkan uraian di atas, maka dapat diambil permasalahan penelitian ini yaitu: (1) apakah performance expectancy dan effort expectancy memengaruhi penggunaan SIORTU melalui minat penggunaan SIORTU; (2) bagaimana pengaruh setiap faktor-faktor yang diasumsikan terhadap minat dan penggunaan SIORTU; dan (3) bagaimana keterkaitan hasil penelitian ini dengan penelitian oleh Bashir [3]. Dari tiga rumusan masalah tersebut, dapat ditarik asumsi bahwa performance expectancy dan effort expectancy lebih mungkin memengaruhi penggunaan SIORTU melalui minat penggunaan SIORTU. Selain itu, dapat diasumsikan pula bahwa social influence dapat memengaruhi minat penggunaan SIORTU. Hal ini didasari oleh penelitian Venkatesh et al [6]. Asumsi selanjutnya adalah facilitating condition dan habit memengaruhi minat penggunaan SIORTU. Asumsi ini dibangun berdasarkan penelitian Venkatesh et al [10]. Adapun behavioral intention diasumsikan memengaruhi perilaku penggunaan SIORTU. Nilai positif hasil analisis dianggap memenuhi asumsi bahwa suatu variabel berpengaruh terhadap variabel lain [10].

\section{METODE}

Penelitian ini merupakan penelitian kuantitatif dengan metode survey menggunakan kuesioner. Survey dilakukan kepada orang tua/wali mahasiswa UII melalui online menggunakan email orang tua/wali mahasiswa [3]. Adapun email orang tua/wali mahasiswa diperoleh dari BSI UII. Hasil pengumpulan data menggunakan kuesioner berupa angka., dianalisis dengan perangkat lunak SmartPLS 3.2 .

Variabel-variabel yang dipilih diperoleh dari penelitian-penelitian sebelumnya yang menyatakan suatu variabel berpengaruh positif dan signifikan terhadap minat penggunaan dan penggunaan suatu sistem. Hasil studi pustaka oleh Bashir menunjukkan bahwa beberapa variabel penelitian yang diteliti antara lain performance expectancy (harapan kinerja), effort expectancy (harapan usaha), social influence (pengaruh sosial), facilitating conditions (kondisi-kondisi yang memfasilitasi), habit (kebiasaan), behavioral intention (minat penggunaan) dan usage behavior (perilaku penggunaan) [3].

Performance expectancy atau harapan kinerja yaitu tingkat kepercayaan seseorang merasakan kemudahan pekerjaan karena menggunakan suatu sistem [6]. Harapan kinerja berpengaruh positif signifikan terhadap minat penggunaan [11][12]. Oleh karena itu dapat diasumsikan bahwa harapan kinerja berpengaruh positif signifikan terhadap minat penggunaan SIORTU. Di dalam penelitian ini, variabel ini disebut sebagai Performance Expectancy (PE). Effort expectancy atau harapan usaha memiliki pengaruh positif signifikan terhadap minat penggunaan suatu sistem [6][11][12][13]. Oleh karena itu, dapat diasumsikan bahwa harapan kinerja berpengaruh positif signifikan terhadap minat penggunaan SIORTU. Di dalam penelitian ini, variabel ini disebut sebagai Effort Expectancy (EE).

Social influence atau pengaruh sosial yaitu tingkat kepercayaan seseorang merasakan seharusnya ia menggunakan suatu sistem karena orang yang dianggap penting menggunakan sistem tersebut [6]. Pengaruh sosial memiliki pengaruh yang positif signifikan terhadap minat penggunaan suatu sistem [6][8][9][12][13]. Berdasarkan hasil tersebut, maka diasumsikan bahwa pengaruh sosial berpengaruh positif signifikan terhadap minat penggunaan SIORTU. Di dalam penelitian ini, variabel ini disebut sebagai Social Influence (SI). Facilitating conditions atau kondisi-kondisi yang memfasilitasi yaitu tingkat kepercayaan seseorang terhadap adanya fasilitas pendukung untuk menunjang suatu sistem [6]. Kecenderungan pengguna dalam menggunakan suatu sistem akan semakin meningkat apabila fasilitas yang ada semakin banyak/lengkap [11]. 
Kondisi-kondisi yang memfasilitasi berpengaruh positif dan signifikan terhadap minat penggunaan suatu sistem [8][10]. Oleh karena itu, diasumsikan bahwa kondisi-kondisi yang memfasilitasi berpengaruh positif dan signifikan terhadap minat penggunaan SIORTU. Di dalam penelitian ini, variabel ini disebut sebagai Facilitating Conditions (FC). Habit atau kebiasaan yaitu tingkat kecenderungan seseorang untuk melakukan suatu perilaku secara otomatis karena pengalaman sebelumnya [10]. Penelitian oleh Venkatesh, dkk menunjukkan hasil positif signifikan terhadap minat penggunaan suatu sistem [10]. Oleh karena itu, diasumsikan bahwa kebiasaan berpengaruh terhadap minat penggunaan SIORTU. Di dalam penelitian ini, variabel Habit atau kebiasaan disebut sebagai Habit $(\mathrm{Hb})$.

Behavioral intention atau minat penggunaan yaitu minat seseorang untuk mulai menggunakan suatu sistem [3]. Penggunaan suatu sistem dipengaruhi oleh minat penggunaan [6], [14]-[16]. Keyakinan karena diperolehnya imbalan yang disebabkan penggunaan suatu sistem, akan memengaruhi minat penggunaan terhadap penggunaan suatu sistem itu sendiri [10], [16]. Minat penggunaan berpengaruh positif signifikan terhadap penggunaan suatu sistem [10]. Oleh karena itu, diasumsikan bahwa minat penggunaan berpengaruh positif signifikan terhadap perilaku penggunaan SIORTU. Variabel ini disebut sebagai SIORTU Behavioral Intention (SBI). Usage behavior atau perilaku penggunaan yaitu perilaku pengguna yang akan menggunakan suatu sistem pada masa mendatang [6]. Perilaku penggunaan yaitu keinginan seorang pengguna untuk terus menggunakan suatu sistem. Variabel ini selanjutnya disebut sebagai SIORTU Usage Behavior (SUB) [17].

Berdasarkan berbagai penjelasan mengenai variabel penelitian sebelumnya, maka dapat ditentukan kerangka penelitian yang tampak pada Gambar 1. Adapun hipotesis penelitian ini sebagai berikut.
H1: Performance expectancy berpengaruh positif signifikan terhadap SIORTU behavioral intention

H2: Effort expectancy berpengaruh positif signifikan terhadap SIORTU behavioral intention

H3: Social influence berpengaruh positif signifikan terhadap SIORTU behavioral intention

H4: Facilitating conditions berpengaruh positif signifikan terhadap SIORTU behavioral intention

H5: Habit berpengaruh positif signifikan terhadap SIORTU behavioral intention

H6: SIORTU behavioral intention berpengaruh positif signifikan terhadap SIORTU usage behavior

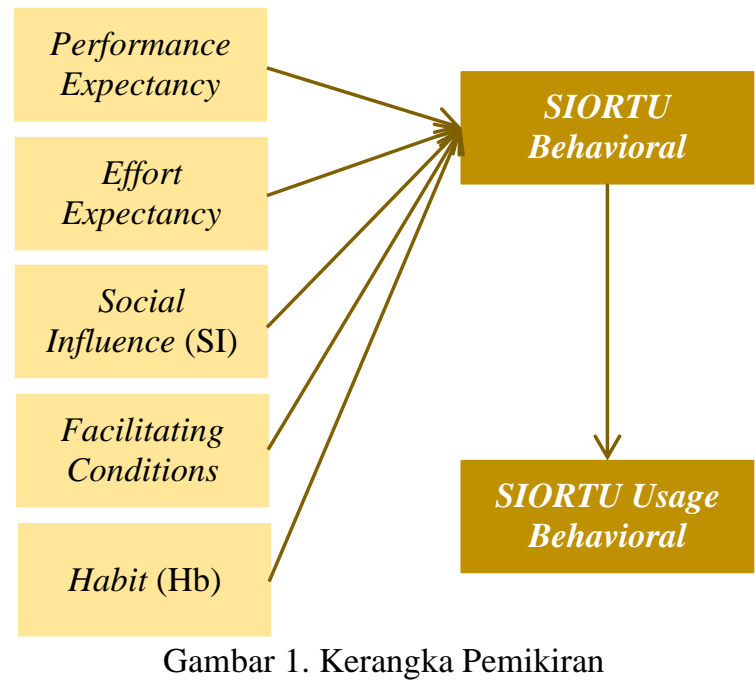

Penelitian ini menggunakan kuesioner sebagai metode pengumpulan data. Kuesioner merupakan daftar pertanyaan atau angket [18]. Instrumen penelitian merupakan bagian kuesioner yang dirancang sebelum kuesioner didistribusikan. Penelitian ini mengadaptasi instrumen penelitian Bashir [3]. Perubahan instrument penelitian terhadap instrumen tersebut ditunjukkan pada Tabel 1. Perubahan penyebutan variabel ini dilakukan untuk menyesuaikan dengan nama masing-masing variabel agar lebih mudah dipahami. Variabel Performance Expectancy (PE) memiliki dua indikator variabel, variabel Effort Expectancy (EE) memiliki 5 indikator variabel, variabel 
Social Influence (SI) memiliki 4 indikator variabel, variabel Facilitating Conditions (FC) memiliki 4 indikator variabel, variabel Habit $(\mathrm{Hb})$ memiliki 3 indikator variabel, variabel SIORTU Behavioral Intention (SBI) memiliki 4 indikator variabel, dan variabel SIORTU Usage Behavior (SUB) memiliki 4 indikator variabel. Total item pertanyaan pada kuesioner adalah 26 item.

Tabel 1. Instrumen Penelitian [3]

\begin{tabular}{|c|c|c|c|}
\hline Variabel & $\begin{array}{l}\text { Indikator } \\
\text { Variabel } \\
\end{array}$ & Item Pertanyaan & $\begin{array}{c}\text { Nomor } \\
\text { item }\end{array}$ \\
\hline \multirow{2}{*}{$\begin{array}{l}\text { Performance } \\
\text { Expectancy } \\
\text { (PE) }\end{array}$} & PE1 [6] & $\begin{array}{l}\text { SIORTU dapat membantu Saya dalam pemantauan kegiatan } \\
\text { akademik anak Saya. }\end{array}$ & 1 \\
\hline & PE2[6] & $\begin{array}{l}\text { Menggunakan SIORTU memungkinkan Saya memantau kegiatan } \\
\text { akademik anak saya dengan lebih cepat }\end{array}$ & 2 \\
\hline \multirow{5}{*}{$\begin{array}{c}\text { Effort } \\
\text { Expectancy } \\
\text { (EE) }\end{array}$} & EE1 [6] & Interaksi dalam SIORTU jelas dan mudah dimengerti & 3 \\
\hline & EE2 [6] & Mudah bagi Saya untuk mempelajari penggunaan SIORTU & 4 \\
\hline & EE3 [6] & $\begin{array}{l}\text { Menggunakan SIORTU menjadikan pemantauan kegiatan akademik } \\
\text { anak saya lebih efisien dalam segi tenaga dan waktu }\end{array}$ & 5 \\
\hline & EE4 [6] & $\begin{array}{l}\text { Saya percaya SIORTU memudahkan Saya dalam memantau } \\
\text { kegiatan akademik anak Saya. }\end{array}$ & 6 \\
\hline & EE5 [19] & Saya dapat dengan mudah mengakses SIORTU & 7 \\
\hline \multirow{4}{*}{$\begin{array}{l}\text { Social } \\
\text { Influence } \\
\text { (SI) }\end{array}$} & SI1 [20] & $\begin{array}{l}\text { Pihak kampus mewajibkan orang tua mahasiswa untuk } \\
\text { menggunakan SIORTU }\end{array}$ & 8 \\
\hline & SI2 [20] & Pihak kampus menyaranan saya untuk mengunakan SIORTU & 9 \\
\hline & SI3 [20] & Anak saya yang mengingatkan saya untuk menggunakan SIORTU & 10 \\
\hline & SI4 [7], [21] & $\begin{array}{l}\text { Saya menggunakan SIORTU karena Saya tahu orang tua/ wali } \\
\text { mahasiswa yang lain juga menggunakan SIORTU. }\end{array}$ & 11 \\
\hline \multirow{4}{*}{$\begin{array}{l}\text { Facilitating } \\
\text { Conditions } \\
\text { (FC) }\end{array}$} & FC1 [6] & $\begin{array}{l}\text { Saya memiliki sumber daya yang diperlukan (misal: smartphone, } \\
\text { PC, dll) untuk menggunakan SIORTU. }\end{array}$ & 15 \\
\hline & FC2 [6] & $\begin{array}{l}\text { Saya memiliki pengetahuan yang diperlukan untuk menggunakan } \\
\text { SIORTU. }\end{array}$ & 16 \\
\hline & FC3 [7], [21] & Saya mendapatkan panduan penggunaan SIORTU & 17 \\
\hline & FC4 [6] & $\begin{array}{l}\text { keluarga dan kerabat) ketika saya mengalami kesulitan dalam } \\
\text { menggunakan SIORTU. }\end{array}$ & 18 \\
\hline \multirow{3}{*}{ Habit $(\mathrm{Hb})$} & & & 12 \\
\hline & & di kebiasaan bagi saya & 13 \\
\hline & 3 [10] & Saya & 14 \\
\hline \multirow{4}{*}{$\begin{array}{l}\text { SIORTU } \\
\text { Behavioral } \\
\text { Intention } \\
\text { (SBI) }\end{array}$} & SBI1 [10] & Saya berniat untuk seterusnya menggunakan SIORTU & 19 \\
\hline & SBI2 [6] & $\begin{array}{l}\text { Saya berusaha menggunakan SIORTU demi mengetahui aktivitas } \\
\text { akademik anak saya. }\end{array}$ & 20 \\
\hline & SBI3 [6] & $\begin{array}{l}\text { Kedepannya Saya tetap menggunakan SIORTU agar aktivitas } \\
\text { akademik anak Saya terus terpantau. }\end{array}$ & 21 \\
\hline & SBI4 [19] & $\begin{array}{l}\text { Saya rasa menggunakan SIORTU menjadi langkah yang tepat dalam } \\
\text { pemantauan akademik anak }\end{array}$ & 22 \\
\hline \multirow{4}{*}{$\begin{array}{l}\text { SIORTU } \\
\text { Usage } \\
\text { Behavior } \\
\text { (SUB) }\end{array}$} & SUB1 [6] & Saya sering menggunakan SIORTU & 23 \\
\hline & SUB2 [6] & $\begin{array}{l}\text { Saya biasa memantau perkembangan aktivitas akademik anak } \\
\text { melalui SIORTU }\end{array}$ & 24 \\
\hline & SUB3 [6] & $\begin{array}{l}\text { Saya lebih memilih menggunakan SIORTU dari pada harus } \\
\text { mendatangi/ menghubungi pihak kampus }\end{array}$ & 25 \\
\hline & SUB4 [19] & Saya menggunakan SIORTU dengan durasi sesuai kebutuhan & 26 \\
\hline
\end{tabular}

Analisis data yang dilakukan meliputi uji validitas, uji reliabilitas, analisis nilai Original Sampel Estimate dan analisis nilai T Statistic. Pengujian hipotesis dilakukan berdasarkan hasil analisis nilai Original Sampel Estimate dan nilai
$T$ Statistics. Alat yang digunakan untuk melakukan analisis data adalah perangkat lunak SmartPLS 3.2. Uji validitas adalah pengujian yang dilakukan untuk mengetahui kesesuaian angket. Hasil penghitungan SmartPLS 3.2 yang 
digunakan sebagai dasar uji validitas yaitu nilai Factor Loading. Nilai Factor Loading seharusnya menunjukkan angka lebih dari 0,7 agar angket dinyatakan valid [7]. Indikator variabel yang dinyatakan tidak valid selanjutnya dihapus [22] dan dilakukan pengujian ulang. Uji reliabilitas adalah pengujian yang dilakukan untuk mengetahui tingkat konsistensi variabel penelitian. Uji reliabilitas ditentukan dari nilai Composite Reliability pada perangkat lunak SmartPLS 3.2. Nilai Composite Reliability seharusnya memiliki nilai lebih dari 0,6 agar angket lolos uji reliabilitas [23].

Nilai $R$ Square menunjukkan besarnya pengaruh variabel bebas terhadap variabel terikat. Nilai $R$ Square dibagi menjadi tiga kategori yaitu kuat (memiliki nilai 0,67), moderat (memiliki nilai 0,33) dan lemah (memiliki nilai 0,19) [23]. Nilai Original Sample Estimate menunjukkan arah pengaruh variabel bebas terhadap variabel terikat. Nilai positif pada Original Sample Estimate menunjukkan variabel bebas pengaruh positif terhadap variabel terikat, sedangkan nilai negatif menunjukkan variabel bebas berpengaruh negatif atau berlawanan terhadap variabel terikat. Nilai $T$ Statistics menunjukkan besarnya pengaruh signifikan variabel bebas terhadap variabel terikat. Variabel bebas dinyatakan berpengaruh signifikan terhadap variabel terikat apabila nilai T Statistics menunjukkan angka lebih dari 1,9 [23]. Uji hipotesis dilakukan berdasarkan nilai Original Sample Estimate dan nilai T Statistics.

\section{HASIL DAN PEMBAHASAN}

Hasil uji validitas menunjukkan empat indikator variabel memiliki nilai Factor Loading kurang dari 0,7. Di antara angket yang dinyatakan tidak valid antara lain SI3, SI4, FC3 dan FC 4. Keempat indikator variabel tersebut berturut-turut memiliki nilai Factor Loading sebesar 0,637; 0,494; 0,573 dan 0,529. Adapun hasil uji validitas setelah keempat indikator variabel dihapus, tampak pada Tabel 1. Tabel 2 menunjukkan semua angket dinyatakan valid karena memiliki nilai Factor Loading di atas 0,7. Nilai Factor Loading terkecil dimiliki oleh
SUB3 sebesar 0,709. Selanjutnya dilakukan hasil uji reliabilitas. Hasil uji reliabilitas tampak pada Tabel 3.

Tabel 2. Hasil Uji Validitas

\begin{tabular}{ccc}
\hline $\begin{array}{c}\text { Indikator } \\
\text { Variabel }\end{array}$ & $\begin{array}{c}\text { Nilai } \\
\text { Factor Loading }\end{array}$ & $\begin{array}{c}\text { Hasil } \\
\text { Uji Validitas }\end{array}$ \\
\hline PE1 & 0.983 & Valid \\
PE2 & 0.978 & Valid \\
EE1 & 0.787 & Valid \\
EE2 & 0.797 & Valid \\
EE3 & 0.824 & Valid \\
EE4 & 0.815 & Valid \\
EE5 & 0.75 & Valid \\
SI1 & 0.725 & Valid \\
SI2 & 0.967 & Valid \\
FC1 & 0.9 & Valid \\
FC2 & 0.88 & Valid \\
Hb1 & 0.77 & Valid \\
Hb2 & 0.964 & Valid \\
Hb3 & 0.947 & Valid \\
SBI1 & 0.866 & Valid \\
SBI2 & 0.959 & Valid \\
SBI3 & 0.954 & Valid \\
SBI4 & 0.854 & Valid \\
SUB1 & 0.815 & Valid \\
SUB2 & 0.873 & Valid \\
SUB3 & 0.709 & Valid \\
SUB4 & 0.884 & Valid \\
\hline
\end{tabular}

Tabel 3. Hasil Uji Reliabilitas

\begin{tabular}{ccc}
\hline Variabel & $\begin{array}{c}\text { Nilai Composite } \\
\text { Reliability }\end{array}$ & $\begin{array}{c}\text { Hasil } \\
\text { Uji Reliabilitas }\end{array}$ \\
\hline PE & 0.98 & Reliabel \\
EE & 0.896 & Reliabel \\
SI & 0.841 & Reliabel \\
FC & 0.884 & Reliabel \\
Hb & 0.925 & Reliabel \\
SBI & 0.95 & Reliabel \\
SUB & 0.893 & Reliabel \\
\hline
\end{tabular}

Pada Tabel 3 terlihat bahwa semua nilai Composite Reliability menunjukkan angka lebih besar dari 0,6. Nilai Composite Reliability terkecil yaitu variabel social influence sebesar 0,841 . Hasil tersebut menunjukkan semua variabel penelitian dinyatakan reliabel atau konsisten. Hasil pengunaan kuesioner yang valid dan reliabel menunjukkan bahwa kuesioner sebagai pengumpulan data untuk menguji hipotesis layak digunakan [24]. Hasil analisis menunjukkan nilai $R$ Square sebesar 0,56 untuk variabel SBI dan 0,328 untuk variabel SUB. Dari 
perolehan nilai tersebut, maka kategori besarnya pengaruh variabel bebas terhadap variabel terikat adalah moderat untuk variabel independen terhadap SBI dan lemah untuk variabel SBI terhadap SUB. Variabel bebas dinyatakan berpengaruh signifikan terhadap variabel terikat apabila nilai $\mathrm{T}$ Statistics menunjukkan angka lebih dari 1,9 [23]. Hasil penghitungan dengan menggunakan perangkat lunak SmartPLS 3.2 menunjukkan hasil seperti terlihat pada Tabel 4 .

Tabel 4. Nilai Pengaruh Variabel Bebas Terhadap Variabel Terikat

\begin{tabular}{|c|c|c|c|}
\hline $\begin{array}{c}\text { Pengaruh } \\
\text { Antar } \\
\text { Variabel }\end{array}$ & $\begin{array}{c}\text { Nilai } \\
\text { Original } \\
\text { Sample }\end{array}$ & $\begin{array}{c}\text { Nilai } \\
T \text { Statistics }\end{array}$ & Keterangan \\
\hline PE -> SBI & 0.28 & 2.735 & $\begin{array}{c}\text { Positif } \\
\text { Signifikan }\end{array}$ \\
\hline PE -> SUB & 0.16 & 2.367 & $\begin{array}{c}\text { Positif } \\
\text { Signifikan }\end{array}$ \\
\hline $\mathrm{EE}->\mathrm{SBI}$ & 0.11 & 0.799 & $\begin{array}{c}\text { Positif Tidak } \\
\text { Signifikan }\end{array}$ \\
\hline EE -> SUB & 0.063 & 0.755 & $\begin{array}{c}\text { Positif Tidak } \\
\text { Signifikan }\end{array}$ \\
\hline SI $->$ SBI & 0.018 & 0.169 & $\begin{array}{c}\text { Positif Tidak } \\
\text { Signifikan }\end{array}$ \\
\hline SI $->$ SUB & 0.01 & 0.168 & $\begin{array}{c}\text { Positif Tidak } \\
\text { Signifikan }\end{array}$ \\
\hline $\mathrm{FC}->\mathrm{SBI}$ & 0.482 & 3.947 & $\begin{array}{c}\text { Positif } \\
\text { Signifikan }\end{array}$ \\
\hline FC $\rightarrow$ SUB & 0.276 & 3.206 & $\begin{array}{c}\text { Positif } \\
\text { Signifikan }\end{array}$ \\
\hline $\mathrm{Hb}->\mathrm{SBI}$ & 0.028 & 0.269 & $\begin{array}{c}\text { Positif Tidak } \\
\text { Signifikan }\end{array}$ \\
\hline $\mathrm{Hb}->$ SUB & 0.016 & 0.255 & $\begin{array}{c}\text { Positif Tidak } \\
\text { Signifikan }\end{array}$ \\
\hline SBI -> SUB & 0.572 & 7.161 & $\begin{array}{c}\text { Positif } \\
\text { Signifikan }\end{array}$ \\
\hline
\end{tabular}

Tabel 4 menunjukan nilai pengaruh variabel bebas terhadap variabel terikat berdasarkan nilai Original Sample Estimate dan T Statistics. Hasil analisis nilai Original Sample Estimate pada Tabel 4 menunjukan bahwa semua variabel bebas memiliki pengaruh yang positif terhadap variabel SBI. Hasil serupa tampak pada variabel bebas yang berpengaruh positif terhadap variabel SUB melalui variabel SBI. Adapun nilai $T$ Statistics yang diperoleh memiliki nilai yang berbeda-beda. Hal ini menunjukkan bahwa ada beberapa variabel bebas yang memiliki pengaruh yang tidak signifikan terhadap variabel terikat. Uji hipotesis dilakukan berdasarkan nilai Original Sample Estimate dan nilai T Statistics. Tabel 4 menunjukkan beberapa variabel memiliki pengaruh positif signifikan terhadap variabel SBI maupun SUB melalui SBI.

Penelitian Bashir menunjukkan bahwa tidak terbukti variabel PE yang diasumsikan secara langsung memengaruhi penggunaan SIORTU [3]. Perbedaan sistem yang diteliti dan objek penelitian dapat memengaruhi hasil penelitian yang dilakukan [3]. Berbeda dengan hasil pengembangan penelitian yang dilakukan oleh penulis. Berdasarkan Tabel 4, hasil analisis menunjukkan bahwa variabel PE memiliki pengaruh positif signifikan terhadap SBI maupun SUB melalui SBI. Hal ini sejalan dengan penelitian oleh Venkatesh et al. yang menyatakan variabel PE berpengaruh terhadap minat penggunaan suatu sistem [6]. Hal yang tidak jauh berbeda juga ditemukan pada Nyembezi \& Bayaga, bahwa harapan kinerja berpengaruh signifikan terhadap minat perilaku [25]. Hasil penelitian yang dilakukan menunjukan bahwa penggunaan SIORTU tidak langsung dipengaruhi oleh harapan kinerja, namun melalui minat penggunaan SIORTU. Adapun harapan kinerja akan memengaruhi minat menggunakan SIORTU. Berdasarkan analisis yang dilakukan menunjukkan penggunaan SIORTU dipengaruhi oleh minat penggunaan SIORTU.

Variabel EE tidak terbukti berpengaruh langsung terhadap penggunaan SIORTU [3]. Hasil penelitian pada penelitian tersebut menunjukkan angka negatif. Bashir menjelaskan bahwa variabel EE tidak berpengaruh langsung terhadap penggunaan SIORTU karena pengguna masih memerlukan usaha dan waktu dalam menggunakan SIORTU [3]. Alasan tersebut nampaknya berpengaruh pula terhadap minat penggunaan SIORTU. Oleh karena pengguna masih memerlukan usaha dan waktu dalam menggunakan SIORTU, maka minat pengguna dalam menggunakan SIORTU- 
pun belum signifikan. Hasil penelitian oleh penulis menunjukkan EE hanya berpengaruh positif terhadap SBI dan SUB melalui SBI.

Variabel SI terbukti memengaruhi penggunaan SIORTU secara langsung [3]. Hasil penelitian tersebut menunjukkan variabel SI berpengaruh positif signifikan terhadap penggunaan SIORTU. Hasil tersebut tidak terbukti apabila variabel SI diasumsikan memengaruhi SBI dan SUB melalui SBI. Hasil analisis oleh penulis menunjukkan bahwa variabel SI hanya berpengaruh positif namun tidak signifikan baik terhadap SBI maupun SUB melalui SBI. Hal ini menunjukkan bahwa pengaruh sosial menjadi salah satu faktor yang memengaruhi minat penggunaan SIORTU, meskipun pengaruh tersebut belum signifikan.

Bashir membuktikan FC sebagai faktor yang memengaruhi penggunaan SIORTU secara langsung [3]. Di dalam penelitiannya, dijelaskan kondisi-kondisi yang memfasilitasi berpengaruh terhadap penggunaan SIORTU. Hasil tersebut sejalan dengan hasil penelitian oleh penulis. Penulis mengasumsikan bahwa variabel FC berpengaruh terhadap minat penggunaan SIORTU. Berdasarkan hasil analisis pada Tabel 4, variabel FC terbukti berpengaruh terhadap minat penggunaan SIORTU dan penggunaan SIORTU melalui minat penggunaan SIORTU. Hal ini menunjukkan kondisi-kondisi yang memfasilitasi berpengaruh terhadap minat pengguna dalam menggunakan SIORTU. Hasil penelitian ini sejalan pula dengan penelitian Venkatesh et al. yang mengasumsikan variabel FC berpengaruh terhadap minat penggunaan suatu sistem [10]. Berdasarkan hasil yang ada, maka variabel FC merupakan faktor yang memengaruhi minat penggunaan SIORTU.

Variabel $\mathrm{Hb}$ tidak terbukti berpengaruh terhadap minat penggunaan SIORTU pada penelitian oleh penulis. Hasil penelitian yang dilakukan hanya menunjukkan nilai positif namun tidak signifikan antara $\mathrm{Hb}$ terhadap SBI maupun $\mathrm{Hb}$ terhadap SUB melalui SBI. Hal ini berbeda dengan hasil penelitian Venkatesh et al. yang menunjukkan bahwa $\mathrm{Hb}$ berpengaruh terhadap minat penggunaan suatu sistem [10].
$\mathrm{Hb}$ lebih mungkin memengaruhi penggunaan SIORTU secara langsung [3]. Variabel SBI berpengaruh positif dan signifikan terhadap SUB [3] [6]. Hasil yang menunjukkan SBI berpengaruh positif signifikan terhadap SUB ditunjukkan pada Tabel 4. Hal tersebut menunjukkan bahwa pengguna menggunakan suatu sistem karena dipengaruhi oleh minat menggunakan sistem tersebut.

Keterlibatan orang tua dalam pendidikan anak terbukti memiliki efek positif yang signifikan pada kesejahteraan anak [26]. Minat orang tua menggunakan SIORTU dipengaruhi oleh harapan kinerja dan tingkat kepercayaan seseorang terhadap adanya fasilitas pendukung. Orang tua akan menggunakan SIORTU apabila memiliki minat, harapan kinerja dan percaya terhadap kondisi fasilitas pendukung sistem. Sistem informasi orangtua harus dapat menghadirkan harapan kinerja, kondisi fasilitas dan minat. Penelitian kedepan perlu mengkaji cara suatu sistem informasi menghadirkan variabel-variabel tersebut.

\section{SIMPULAN}

Berdasarkan hasil penelitian yang telah dijabarkan di atas, maka dapat ditarik kesimpulan sebagai berikut: (1) Performance Expectancy dan Effort Expectancy terbukti memengaruhi penggunaan SIORTU melalui minat penggunaan SIORTU, namun keduanya memiliki nilai pengaruh yang berbeda. Performance Expectancy memiliki pengaruh positif signifikan terhadap penggunaan SIORTU melalui minat penggunaan SIORTU, sedangkan Effort Expectancy hanya berpengaruh positif terhadap penggunaan SIORTU melalui minat penggunaan SIORTU; (2) Semua variabel bebas yang diteliti terbukti memengaruhi minat penggunaan SIORTU dan penggunaan SIORTU melalui minat penggunaan SIORTU sehingga dinyatakan sebagai faktor yang memengaruhi minat penggunaan SIORTU, meskipun nilai pengaruh masing-masing variabel berbeda. Berdasarkan hasil analisis hanya Performance Expectancy dan Facilitating Conditions yang memiliki nilai positif signifikan terhadap minat 
penggunaan SIORTU dan penggunaan SIORTU melalui minat penggunaan SIORTU. Adapun variabel Effort Expectancy, Social Influence dan Habit hanya memiliki pengaruh positif namun tidak signifikan terhadap minat penggunaan SIORTU dan penggunaan SIORTU melalui minat penggunaan SIORTU; dan (3) Penelitian oleh Bashir [3] memiliki kaitan dengan penelitian yang dilakukan oleh penulis. Variabel Performance Expectancy terbukti memiliki nilai positif signifikan terhadap penggunaan SIORTU melalui minat penggunaan SIORTU. Variabel Effort Expectancy tidak terbukti secara langsung dalam memengaruhi penggunaan SIORTU, namun terbukti memengaruhi penggunaan SIORTU melalui minat penggunaan SIORTU. Variabel Facilitating Conditions terbukti berpengaruh positif signifikan terhadap penggunaan SIORTU baik secara langsung maupun melalui minat penggunaan SIORTU. Social Influence dan Habit berpengaruh positif terhadap penggunaan SIORTU baik secara langsung maupun melalui minat penggunaan SIORTU, meskipun melalui minat penggunaan SIORTU hanya bernilai positif tidak signifikan.

\section{DAFTAR PUSTAKA}

[1] H. A. E. Widjaja, "Implementasi Portal Layanan Bagi Orang Tua Mahasiswa Pada Perguruan Tinggi," vol. 2010, no. semnasIF, pp. 91-96, 2010.

[2] A. Setiawan, "Analisis Sistem Informasi Orang Tua Wali Mahasiswa berbasis Website Studi Kasus Universitas Muhammadiyah Magelang," J. Inform. Upgris, vol. 2, no. 1, pp. 8-17, 2016.

[3] N. A. A. Bashir, "Analisis Faktor-Faktor yang Memengaruhi Penggunaan Sistem Informasi Akademik Khusus Orang Tua," Universitas Islam Indonesia, 2020.

[4] E. F. Febrianti, "Analisis Faktor-Faktor yang Mempengaruhi Penggunaan Sistem Informasi Berbasis Komputer," 2017.

[5] F. Agustine, "Pengaruh Ekspektasi Kinerja, Ekspektasi Usaha, Faktor Sosial dan Kepuasan Pemakai Terhadap Penggunaan Sistem Informasi Berbasis Komputer pada Perusahaan Penerbitan di Surakarta," Universitas Sebelas Maret, 2009.

[6] V. Venkatesh, M. G. Morris, G. B. Davis, and F. D. Davis, "User Acceptance of Information Technology: Toward A Unified View," MIS Q., vol. 27, no. 3, pp. 425-478, 2003.
[7] N. Auliya, "Penerapan Model Unified Theory of Acceptance and Use Of Technology 2 Terhadap Minat dan Perilaku Penggunaan E-Ticket di Yogyakarta," Universitas Islam Indonesia, 2018.

[8] T. Handayani and S. Sudiana, "Analisis Penerapan Model Utaut (Unified Theory of Acceptance and Use of Technology) Terhadap Perilaku Pengguna Sistem Informasi (Studi Kasus: Sistem Informasi Akademik Pada Sttnas Yogyakarta)," Angkasa J. Ilm. Bid. Teknol., vol. 7, no. 2, pp. 165-180, 2015.

[9] R. Mustaqim, A. Kusyanti, and H. Aryadita, "Analisis Faktor-Faktor yang Memengaruhi Niat Penggunaan E-Commerce XYZ Menggunakan Model UTAUT (Unified Theory Acceptance and Use Of Technology)," J. Pengemb. Teknol. Inf. dan Ilmu Komput., vol. 2, no. 7, pp. 2584-2593, 2018.

[10] V. Venkatesh, J. Y. L. Thong, and X. Xu, "Consumer Acceptance and Use Of Information Technology: Extending The Unified Theory Of Acceptance and Use Of Technology," MIS Q., vol. 36, no. 1, pp. 157-178, 2012.

[11]R. Handayani, "Analisis Faktor-Faktor yang Mempengaruhi Minat Pemanfaatan Sistem Informasi dan Penggunaan Sistem Informasi ( Studi Empiris Pada Perusahaan Manufaktur di Bursa Efek Jakarta ),” J. Akunt. dan Keuang., vol. 9, no. 2, pp. 76-88, 2007.

[12] M. Sitanggang, R. K. J. Bendi, and F. Soejono, "Analisis Perilaku Penggunaan Sistem Informasi Akademik Oleh Mahasiswa Keperawatan," JuSiTik J. Sist. dan Teknol. Inf. Komun., vol. 1, no. 1, p. 11, 2017.

[13]F. Fiddin, K. Kamaliah, and H. Hardi, "FaktorFaktor Yang Mempengaruhi Minat Pemanfaatan Sistem Informasi Dan Penggunaan Sistem Informasi (Studi Pada Satuan Kerja Perangkat Daerah Pemerintah Provinsi Riau)," Sorot, vol. 8, no. 1, p. 77, 2013.

[14]F. D. Davis, "Perceived Usefulness, Perceived Ease of Use, and User Acceptance of Information Technology," MIS Q., vol. 13, no. 0, pp. 319-340, 1989.

[15] W. H. DeLone and E. R. McLean, "The DeLone and McLean Model of Information System Success," J. Manag. Inf. Syst., vol. 19, no. 4, pp. 9-30, 2003.

[16] R. L. Thompson, Hanggings, A. Christoper, and J. M. Howell, "Personal Computing: Toward a Conceptual Model of Utilization," MIS Q., vol. 15, no. 1, pp. 125-143, 1991.

[17]B. Raharjo, H. Adi Nugroho, and W. Wahyu Winarno, "Analisis Faktor Determinan Penggunaan Sistem Informasi Sumber Daya Manusia Dan Implikasinya Terhadap Reformasi Birokrasi Pada Bpk Ri,” J. Inform., vol. 10, no. 1, pp. 1149-1155, 2016. 
[18]E. Endarmoko, Tesaurus Bahasa Indonesia, Kedua. Jakarta: Gramedia Pustaka Utama, 2007.

[19]H. W. Sulistyo, "Evaluasi Penerimaan Mahasiswa Terhadap Sistem Informasi Akademik (SIA) Menggunakan TAM 3 Di Universitas Muhammadiyah Jember," Universitas Islam Indonesia, 2017.

[20] V. Venkatesh and F. D. Davis, “A Theoretical Extension of the Technology Acceptance Model : Four Longitudinal," Manage. Sci., vol. 42, no. 2, pp. 186-204, 2000.

[21]N. Bahiyah, "Faktor-Faktor yang Mempengaruhi Minat Pemanfaatan Magnetic Resonance Imaging (MRI)," Universitas Islam Indonesia, 2014.

[22]I. Ghozali, Analisis Multivariate Lanjutan dengan SPSS. Semarang: Badan Penerbit Universitas Diponegoro, 2001.

[23]D. R. Sari, "Pengaruh Dimensi Budaya Terhadap Perilaku Penggunaan E-Commerce: Daerah Istimewa Yogyakarta dan Kalimantan Timur," Universitas Islam Indonesia, 2018.
[24]P. Sudira, D. Santoso, S. Waluyanti, and P. Utami, "Model of Vocational Teachers (Audio Video Engineering) Efforts to Support Graduates' Work Readiness," Int. J. Adv. Sci. Technol., vol. 29, no. 1, pp. 815-827, 2020.

[25]N. Nyembezi and A. Bayaga, "Performance Expectancy and Usage of Information Systems and Technology: Cloud Computing (PEUISTCC)," Int. J. Educ. Sci., vol. 7, no. 3, pp. 579-586, Nov. 2014.

[26] A. Kamaruddin, S. V. A.L. Nagalingam, N. Admodisastro, and N. S. M. Rasid, "Parent personal information system to improve parental involvement in children's learning process in elementary school," in 2014 3rd International Conference on User Science and Engineering ( $i$ USEr), 2014, pp. 174-179. 